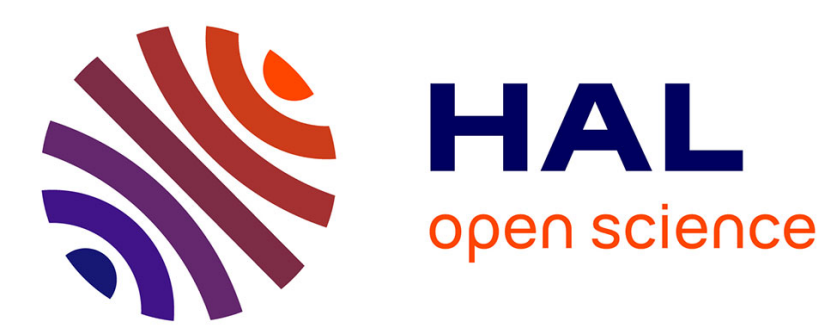

\title{
Word and beyond-word issues in morphological processing
}

\author{
Madeleine Voga, Hélène Giraudo
}

\section{To cite this version:}

Madeleine Voga, Hélène Giraudo. Word and beyond-word issues in morphological processing. Word Structure, 2017, 10 (2), pp.235 - 255. 10.3366/word.2017.0109 . hal-01919081

\section{HAL Id: hal-01919081 https://hal.science/hal-01919081}

Submitted on 15 Jan 2019

HAL is a multi-disciplinary open access archive for the deposit and dissemination of scientific research documents, whether they are published or not. The documents may come from teaching and research institutions in France or abroad, or from public or private research centers.
L'archive ouverte pluridisciplinaire HAL, est destinée au dépôt et à la diffusion de documents scientifiques de niveau recherche, publiés ou non, émanant des établissements d'enseignement et de recherche français ou étrangers, des laboratoires publics ou privés. 


\title{
Word and beyond-word issues in morphological processing
}

\author{
Madeleine Voga and Hélène Giraudo
}

\begin{abstract}
Despite intensive study of morphological effects using various on-line techniques such as masked priming, psycholinguistic accounts of morphological processing have not yet managed to grasp the complexity of the various kinds of relationships between words. We focus on three issues related to aspects of processing that have not been given much importance but can considerably influence the effects we observe. The first issue to be dealt with is the role of frequency of the lexical items used and particularly the role of prime-target relative frequency. Second, 'morphological' effects with nonwords (e.g. sportation-sport), which are very often interpreted as if the status of possible mord did not exist. Finally, the role of a novel variable, pseudo-family size, reflecting the influence of formally related but morphologically unrelated word forms, providing evidence for interference/competition during the early stages of morphological processing. These factors suggest that the complex set of activation/inhibition related to the lexical environment of the word-to-be-identified should be taken into account, and that morphological processing models should try to introduce factors related to the paradigmatic structure of language.
\end{abstract}

Keywords: visual masked priming, lexical access, prime-target relative frequency, nonword effects, visual-perceptive factors, salience, lexicality

\section{Introduction}

Two recent papers (Amenta and Crepaldi 2012 and Diependaele, Grainger and Sandra 2012) presented a detailed review of the last forty years of experimental research on morphological processing. Taking as a starting point the well-established role of morphology during visual word recognition (lexical access), both reviews present the main results to date, having influenced the way in which psycholinguists view complex 
words, their processing and their representation within the mental lexicon, i.e. their locus, nature and access mechanisms. However, none of these reviews introduces a definition of what morphology is, as we might expect in order to better understand the psychological nature and processing mechanisms of morphologically complex words. As in the vast majority of papers dedicated to morphological processing, the authors start instead from a formal description of what a complex word is, e.g. Diependaele et al. (2012) begin their introduction by stating that: 'In linguistics, morphology is defined as the study of internal word structure. Morphemes are the elementary units in this structure, given that they are the smallest units in a language that bear at least some meaning. Depending on whether a word consists of one or several morphemes, it is called morphologically simple or complex' (2012: 311). Amenta and Crepaldi (2012), on the other hand, do not provide any definition of morphology and focus directly on lexical access effects for morphologically complex words. The reader can reasonably draw the conclusion that morphology is reduced to its purely syntagmatic aspects for the former authors, and that, for the latter, psycholinguists are not so keen to discuss the possible links between the very rich linguistic inheritance and its implications for their data, but rather to provide a convincing account for bottom-up processes related to lexical access for complex words.

These two examples point to the fact that a large part of current psycholinguistic literature tends to disregard what should be the starting point of any psycholinguistic research: a reflection of the linguistic characteristics of the object of study, i.e. words. The wealth of linguistic literature on the field of morphology (e.g. Corbin 1987/1991; Aronoff 1994, 2007; Aronoff and Fudeman 2005; Booij 2002, 2015; Blevins 2006; Marantz 2013 and many others) provides an uncontroversial definition: morphology deals both with the internal structure of words (i.e., syntagmatic dimension) and the systematic form-meaning correspondences between them (i.e., paradigmatic dimension). Aside from linguistic debates about which dimension is responsible for the other, i.e., lexeme-based approach vs. morpheme-based approach, the study of the cognitive processes underlying recognition and comprehension of complex words has to take into account both their internal structure and the relationships they bear with other lexical units.

Consider for example the word reader, its internal structure is made up of the base read-and the suffix -er, but it is also embedded in two sets of words:

(1) (a) reader, learner, dancer, writer, etc.

(b) reader, reading, read, readable, unread, misread, etc.

The words in (1a) are all constructed following the same pattern: verbal bases (V) associated with the suffix $-e r$. The agentive function of these words is derived from the series in -er, supporting the meaning pattern 'one who Vs'. Given that the suffix $-e r$ is a bound morpheme which does not have any meaning in isolation, the meaning of the word reader is not simply derived from its internal morphemic structure but also from the fact that the system knows that there are many other words following this pattern. 
The meaning of reader in (1b) also derives from its morphological family, since all these words derive from the verbal base read. In this case, it is the form-meaning comparisons between reader and read, misread and read, that confer to words in $1 \mathrm{~b}$ their meaning, 'a person who reads', 'make a mistake in reading' and so on. This is why morphologists consider that the systematic form-meaning relationships between sets of words, both in terms of series and in terms of families, specify the meaning of any given complex word: this structuring has been found to be relevant for language processing as well as comprehension. Firstly, in terms of morphological families, with the well-known Morphological Family Size effect (e.g. De Jong, Schreuder and Baayen 2000; De Jong, Feldman, Schreuder, Pastizzo and Baayen 2002; Moscoso del Prado Martín, Deutch, Frost, Schreuder, De Jong and Baayen 2005; Mulder, Dijkstra, Schreuder and Baayen 2014), showing that a big morphological family will boost processing of its members, for example in lexical decision experiments; secondly, in terms of morphological series for processing and acquisition (Burani and Thornton 2003; Giraudo and Dal Maso 2016a, 2016b), including for automatic natural language processing (e.g. Hathout 2009).

Consider now the word corner. Encountering this word for the first time, e.g. for a non-native speaker, could possibly lead to compare it to words ending in -er (1a) and to words constructed with the base corn, e.g. corny. However, corner does not match in a set such as la since it matches no verbal base and does not trigger the meaning of the person carrying out the action; nor can it fit in a morphological family (1b), given that the form-meaning correlations between corn and corner are highly inconsistent. From this point of view, corner-corn is a kind of morphological accident, since the cooccurrence in form is not correlated to some relation in meaning. Of course, these accidents are quite frequent in natural languages, which are characterized by plasticity as well as by their trend to reduce signs' arbitrariness (Saussure 2002), creating matches between form and meaning, even when these matches cannot be proven in terms of a morphological relation, such as in folk etymology (e.g. for Greek: Fliatouras, Voga and Anastassiadis-Symeonidis forthcoming). It is however somewhat surprising that the dominant approach on morphological processing has been built on the basis of experimental data - mostly issued from masked priming — taking as critical stimuli words such as corner-corn or baguette-bague in French, ${ }^{1}$ which are not morphologically related (e.g. Longtin and Meunier 2005). In other words, among the huge variety of morphologically related words and the effects that can be observed, the corner-corn effect, combined with bottom-up protocols, is the one that dominated psycholinguistic production for a long time. It has led to an impressive number of studies in various languages (e.g. Rastle, Davis and New 2004; Longtin and Meunier 2005, Rastle and Davis 2008; see also Feldman, O’Connor and Moscoso Del Prado Martín 2009; Giraudo and Dal Maso 2016b, for critical reviews), resulting in a consensus according to which during the early stages of word identification, morphological effects are due to a mechanism of mandatory decomposition. This mechanism is supposed to be automatically applied to the visual appearance of words, from the moment they look complex, in order to segment them into 'morphemes or sub-units resembling morphemes'. The main experimental findings can be summarized as follows: two 
morphologically related word pairs will prime each other, e.g. hunter-hunt, and this facilitation will not differ from that between pseudo-derived primes, e.g. corner - corn. These derivation and pseudo-derivation effects will not be fundamentally different from those induced by nonwords such as sportation, which is able to facilitate the recognition of its pseudo-base sport (e.g. Rastle, Davis and New 2004; and references cited above). Another basic finding of the decompositional account is that the morphologically (or pseudo-morphologically, e.g. corner-corn) structured pairs produce greater priming than non-morphological form pairs, e.g. brothel-broth, where $-e l$ is not a suffix. This finding is taken as evidence that: 'early visual processing of written words is initially concerned with extracting orthographic morphological elements' (Davis and Rastle 2010: 754); and, more importantly, that these effects are not orthographic, as one could assume given the stimuli, setting and protocol used, but properly morphological.

However, a closer investigation of affix relationships within prime-target pairs revealed more complex results that could not fit the decompositional account: Giraudo and Grainger (2003) observed asymmetrical morphological processing of prefixed and suffixed words. They found that prefixed primes (e.g. enjeu-envol, 'stake'-'flight') produced greater priming than both pseudo-affixed primes (e.g. ennui-envol 'boredom'-'flight') and unrelated controls (e.g. biche-envol 'doe'-'flight'), but no comparable suffix priming effect. In contradiction with these data, Duñabeitia, Perea and Carreiras (2008), testing different degrees of prime segmentation e.g. dad$I G U A L D A D$ 'ty'-'equality' (Exp. 1); 2) \%\%\%\%dad-IGUALDAD '\%\%\%\%ty''equality' (Exp. 2); and 3) brevedad-IGUALDAD 'brevity'-'equality' (Exp. 3), found suffix priming effects in Spanish. More precisely, their results revealed significant priming effects with respect to the unrelated control (i.e., aje-igualdad, \%\%\%\%ajigualdad, plumaje-igualdad), in all conditions (i.e., independently of the degree of segmentation of the prime) and a clear dissociation between orthographic and morphological priming (e.g. brevedad primes igualdad but volumen does not prime certamen 'volume'-'contest'). The same authors (Duñabeitia, Perea and Carreiras 2014) underline the impact of individual differences in reading styles, showing that it can modulate the magnitude of the masked transposed-letter priming effects.

In a recent study, Crepaldi, Hemsworth, Davis and Rastle (2016) reinvestigated the affix priming effects using non-words in order to minimize any possible lexical competition between primes and targets (e.g. Davis and Lupker 2006; Segui and Grainger 1990), that may have obscured a suffix in a previous investigation (e.g. Giraudo and Grainger 2003)' (Crepaldi et al. 2016: 115). Their results revealed significant priming effects for the complex pairs, e.g. sheeter-teacher relative to both an orthographic (e.g. sheetal-teacher) and an unrelated control condition (e.g. sheetub-teacher). Conversely, no priming was obtained for the simple word pairs like pollel-barrel which were examined using the same control conditions (i.e., vs. pollic-barrell vs. pollut-barrell). These results have been interpreted as strong evidence in favour of an early pre-lexical morphological decomposition of all forms, both words and nonwords, that can be potentially split into two 'surface morphemes'. Most importantly, these findings are taken as evidence of the 
equal status of access units for both stems and affixes, during the early stages of processing.

Once again, our data are not in agreement with the above interpretation: a recent study by Giraudo and Dal Maso (2016a) with Italian L1 speakers focused on three Italian suffixes, -tore, -ico and -etto with different perceptual characteristics, the series of which present the same functional consistency. The results of this masked priming study indicated clear base priming effects for -tore and -ico targets (e.g. nostalgia-nostalgico 'nostalgia'-'nostalgic'; pescare-pescatore 'to fish'-'fisherman'), but no effect for - etto targets. While the suffix priming condition did not reveal any effect for -tore and -ico (e.g. sinfonico-nostaligico 'symphonic'-'nostalgic'; traditore-pescatore 'traitor'-'fisherman') compared to the unrelated condition, the -etto series yielded the longest RTs. The authors concluded that the different nature of morphological entities might imply different priming effects and that suffixes might need more activation than bases so that facilitation (priming effect) can emerge.

In what follows, we aim to discuss some aspects of morphological priming data, aspects mainly related to the complex set of activation and inhibition exerted during processing of complex stimuli through masked priming protocols. First, as is conventionally done in psycholinguistics, we wish to highlight a methodological issue, specifically the role of prime-target relative frequency in the inherently bottom-up approach of the masked priming technique (section 2). Second, as is scarcely done in morphological processing research and particularly in bottom-up models, we suggest seeing these results in the light of paradigmatic factors and, crucially, in the light of the acknowledgement that words (or pieces of words) do not only have form, but also meaning. The language system tends to create matches on meaning between units or subunits overlapping in form. This issue will be addressed through a brief review of what the literature has described as 'morphological' effects with nonwords (e.g. sportation-sport) in section 3. This issue is closely related to the dichotomy between bottom-up and top-down approaches and the way in which the design of the experiment can, under certain circumstances, possibly circumvent the strictly bottom-up logic of the vast majority of masked priming protocols. The experimental data from French inflections we briefly present in section 4, aiming to demonstrate that it is possible to investigate the complex set of activation-inhibition responsible for morphological priming effects in a more 'integrated' way, i.e. one that allows us adopting a larger window of observation.

\section{Resting level of activation: a neglected factor in morphological accounts}

The masked priming technique implies a prime (e.g. taught) and a target (e.g. teach), the priming benefit being the difference in the time needed to identify the target, compared to an unrelated condition. Given that the most frequently used task for this kind of protocol is the lexical decision task (yes/no) and that above a certain percentage of errors (in most cases 15-20\%, words and non-words together), the performance of a particular participant is not acceptable, since this would mean that he/she did not 
really process the targets, psycholinguists have begun to habitually present as the target the most frequent item: the infinitive for French verbs, the present form for English verbs, or, for protocols examining morphological effects on non-word processing (ex. Meunier and Longtin 2007) the stem-only form, e.g. sport. Nevertheless, in interactive activation (McClelland and Rumelhart 1981) as well as in serial (Forster 1976) models, the surface frequency of the materials plays an important role, given that it defines the 'resting level' or residual activation of a given lexical unit, and consequently, the amount of activation needed to reach the identification threshold. The higher the frequency of the unit, the lower its activation threshold, meaning that less 'effort' is needed in order to activate it. Masked priming protocols are especially subject to this kind of mechanism, given their bottom-up operation mode, and the very short lapse of time the prime has in order to activate the target (Stimulus Onset Asynchronies, SOAs, usually varying between 42 and 57 milliseconds for morphological effects).

The fact that, in the vast majority of masked morphological priming studies, the lexical unit taken as the target is the most frequent one, is not very surprising, at least in the domain of English inflection, where the choice is not very vast: in the verbal system, e.g. in a design to study past tense priming, the target can either be the $1^{\text {st }} / \mathrm{SG}$ or the $3^{\text {rd }} / \mathrm{SG}$ present tense form. As far as derivation is concerned, it is true that taking as target (in a priming experiment with nonword primes, as in Meunier and Longtin 2007) the noun sport, a very frequent word, and not a suffixed unit from the morphological family of [SPORT] (e.g. sportivement 'sportingly', sportif 'athletic', sportive 'athletic'), seems natural to most psycholinguists, after at least fifteen years of morphological processing studies with nonword primes. However, we can wonder why researchers working with this kind of protocol never do the opposite, e.g. sportation - sportivement, or portez - portons 'you carry - we carry', i.e. where the target is not the most frequent word of the family or the paradigm. The implicit assumption here is that all morphologically complex words will be mandatorily decomposed at the entry of the system, independently of their lexical (word or nonword) and activation (frequent or not frequent) status, and consequently there is no need to bother with this kind of design. It is precisely because the dominant decompositional approach assumes that relative frequencies in prime-target pairs should not play any role (e.g. Rastle and Davis 2008; Amenta and Crepaldi 2012 and other references in the introduction), despite data demonstrating the opposite, that the manipulation consisting of 'reversing' the prime-target pairs, has not greatly interested the tenants of the decompositional account until now.

There are however data suggesting an important role for frequency, as we saw above: Among the first to highlight it, Giraudo and Grainger (2000), with French materials, reported larger effects with high-frequency derived primes than with low-frequency ones, as did Meunier and Segui (1999), with spoken primes. The data we present below in some detail (section 4) demonstrate the role of prime-target relative frequencies. Evidence of prime-target relative frequency effects comes also from other languages, e.g. Voga, Giraudo and Anastassiadis-Symeonidis (2012), from Greek verbs, where the basic versus alternative (more frequent) present tense form 
(for the same verb), presents a completely different inflectional effect, when primed by the aorist inflection (which is identical for both).

\section{Is nonword activation pre-lexical, lexical or both? The distinction (and connection) between real word and possible word in bottom-up protocols}

In their review of the most well-documented morphological priming effects (masked and unmasked), such as nonword and frequency effects, Amenta and Crepaldi (2012) reach the conclusion that : 'Surely, morphological effects in non-words exclude the possibility that morphological information only comes into play after lexical identification' (p. 9), given that 'it is clear that nonwords with a morphological structure are analyzed in terms of their morphemes, thus questioning seriously any theory that suggests morphological processing to kick off upon lexical identification' (p. 7). The experimental effects at stake here concern two types of protocols:

a) simple (unprimed) lexical decision tasks, where the participant has to decide if the stimulus is a word or not, and where slower rejection times have been observed for pseudo-inflected nonwords with a real suffix compared to pseudo-inflected words with a real stem and a non-suffix or a non-stem and existing suffix (Burani, Dovetto, Thornton and Laudanna 1997; Burani and Thornton 2003; Caramazza, Laudanna and Romani 1988; Taft and Forster 1975);

b) More recently, masked priming experiments, where the pseudo-inflected real-stem, real-suffix nonword, as we saw in the introduction with the Dunabeitia et al. (2008) study, or jumbled words by letter transpositions, facilitate the identification of the target (i.e., the stem itself), more than other categories of nonwords (e.g. Beyersmann, Duñabeitia, Carreiras, Coltheart and Castles 2013; Christianson, Johnson and Rayner 2005; Diependaele et al. 2013; Duñabeitia, Perea and Carreiras 2007; 2008; Meunier and Longtin 2007, Rueckl and Rimzhim 2011; Sanchez-Gutierrez and Rastle 2013).

The underlying hypothesis here is that the nonwords used in these experiments, including very word-like ones, do not have a lexical representation at all, and that the only way for them to activate one would be through the pre-lexical decomposition mechanism, independently of whether they are constructed upon a very frequent word such as sport (e.g. sportation, in Meunier and Longtin 2007; see also McCormick, Brysbaert and Rastle 2009, in English), of their semantic interpretability (e.g. sportation versus quickify) or their synonymy to existing words, e.g. brightment. The observed 'morphological-like' effects, i.e., longer rejection times in simple lexical decision tasks or shorter reaction times on target identification in masked priming protocols, are supposed to be due to the coding of morphemes at a sub-lexical level of processing, as in Taft's (1994) model (also Crepaldi et al. 2010; Rastle and Davis 2008). 
Two remarks seem important to us at this point: first, as Amenta and Crepaldi (2012) acknowledge, nonword morphological priming effects are characterized by great inconsistency; to cite an example, Burani et al. (2002) obtain no difference between rejection times on suffixed nonwords (e.g. donnista 'womanist') and rejection times on orthographically control nonwords that did not contain any morpheme (e.g. dennosto similar to 'wemanost' in English); this inconsistency is not found for true morphological effects. We have thus a qualitative difference between the pattern for nonwords and for words, which suggests that 'true' morphological effects and 'morphological-like' effects with nonwords may not be strictly equivalent, at least as far as the activation of the base-word representation is concerned, as Giraudo and Voga (2016) demonstrate with French bound-stem word and nonword primes.

Second, the masked priming technique is nevertheless sensitive to orthographic similarity and this is precisely the reason why an orthographic control is used in masked priming protocols in general (e.g. Pastizzo and Feldman 2002; Giraudo and Grainger 2001; 2 Voga and Grainger 2004) and particularly in studies of type (b). Consequently, we can wonder whether it is acceptable to suppose that the orthographic control created by a real stem and a non-suffix, e.g. cantovi, containing the legal stem cant- from CANTARE 'to sing' but a non-existing suffix (or a non-stem and an existing suffix, e.g. canzevi containing a legal verbal affix -evi but a non-legal stem), as in Caramazza et al. (1988) in order to match a suffixed nonword (i.e. with a real stem and a real affix, e.g. cantevi, in the Caramazza study, similar to the English buyed) is equivalent to a real-word orthographic control such as those used in real-word morphological masked priming experiments, e.g. in Pastizzo and Feldman (2002), where fill is the orthographical control for the allomorph fell (see also, e.g. Giraudo and Grainger 2001). In other words, while buyed looks like a real word, the orthographic control to match it does not look like a real word, while both are nonwords.

The bias is evident here, both from a purely theoretical point of view, as well as an experimental one: we know that the border between a possible word and a real word is very thin. Crucially, linguists have extensively documented natural languages' tendency to reduce signs' arbitrariness, through folk etymology for instance, as mentioned in the introduction. As far as experimental data are concerned, it is clear that the system will try to integrate the 'novel word' immediately after exposure, as showed by data demonstrating interference on lexical identification: Bowers, Davis and Hanley (2005a) show that having participants learn new words (e.g. banara) that were neighbours of familiar words that previously had no neighbours (e.g. banana), made it more difficult to semantically categorize the familiar words. This means that interference can also be exerted by items that, at the beginning of the experiment, had no lexical status, but acquired it during the experiment. Moreover, as Bowers et al. (2005a) show, this interference was greater the day following initial exposure. In other words, within a mental lexicon dealing every day with novelty, productivity and lexical creation, able to attribute a (probably temporary) lexical status to an item such as banara, showing no morphological complexity, there is no a priori reason to exclude pord-like items (e.g. sportation, buyed) from the realm of possible words, especially given the morphological pseudo-complexity of these words and the salience of their base/affixes 
(Giraudo and Dal Maso 2016b), which can possibly trigger orthographic bottom-up processing effects. This is especially true for lexical decision experiments where the participant has to make a quick decision on the lexicality of the stimuli presented in the middle of the screen. According to the Multiple Read-out Model (MROM, Grainger and Jacobs 1996; see also Hoffmann and Jacobs 2014), a classic computational model of orthographic processing in visual word recognition based on the interactive activation model (IAM; McClelland and Rumelhart 1981), a 'WORD' response is given when the activation exceeds a certain criterion value. However, correct lexical decisions (Yes/No) can also be made without such lexical access to a certain word representation. This so-called first-pass judgment or fast-guess mechanism is generally said to be based on stimulus familiarity (Jacobs, Graf and Kinder 2003). Which is exactly what several pieces of data interpreted in decompositional terms are doing: nonwords such as sportation, quickify, related to a familiar base, e.g. sport, quick, lead to correct lexical decisions (or delay rejection times), on the basis of orthographic bottom-up activation, without necessarily involving what linguists call morphology, which is supposed to be related to semantics, one way or another (through lexemes or morphemes).

In conclusion, Amenta and Crepaldi's (2012) assumption that the very existence of morphological-type nonword effects refutes all approaches assuming a relation between some kind of lexical identification and morphological effects, which is based on the idea that a nonword like sportation cannot be connected through some kind of link to sport, is in total contradiction with the above findings. This assumption disregards several well established facts: those related to language acquisition, where children produce false yet perfectly intelligible forms (buyed, goed, etc.); those related to productivity (Hay and Baayen 2003; Plag 1999; 2004; Lopez-Villasenor 2012), as well as those related to lexical interference from newly encountered nonwords (Bowers et al. 2005a). In fact, if we consider sportation or buyed as possible pords, linked in some way to a base-lexeme, then much of the data that has been interpreted within the decompositionnal account could be interpreted in the opposite way, i.e., that the pattern of systematic form-meaning correspondences that we call mord morphology (Bybee 1988; 2007, Booij 2002) is extended to novel items every time the system is exposed to novelty.

\section{Exo-lexical variables: the pseudo-family size}

By exo-lexical variables we mean variables situated beyond word boundaries, springing from the complex set of simultaneous activation-inhibition, which constitutes what psycholinguists call the 'overall' activation of the lexicon (Grainger and Jacobs 1996). The morphological family size variable (De Jong, Schreuder and Baayen 2000 and other references cited in the introduction) is such an example. It has been shown to influence word processing: complex words with many morphological relatives will be processed faster than those with a poor morphological family, suggesting that the locus of morphological effects is not restricted to the word-to-be-processed and that elements lying beyond it (here other lexical units from the same family), intervene in 
morphological processing. In the case of the MFS, we can say that words from the same family act as 'synagonists' during processing. Nevertheless, in the mental lexicon 'antagonists' also exist: their role and existence are indicated by neuro-psychological (Massol, Grainger, Dufau and Holcomb 2010) as well as behavioural measures. For example, Grainger, Colé and Segui (1991) demonstrated that orthographic similarity of the prime inhibits lexical access of morphologically complex targets, despite the absence of any morphological relation between them, e.g. the prime mûrir 'ripen' inhibits the target mural 'wall' and this inhibition reaches $27 \mathrm{~ms}$ for words that share their initial letters. This inhibition is accounted for in terms of 'preactivation of lexical representations during the processing of the prime, which interferes with the processing of the target' (Grainger, Colé and Segui 1991: 380).

Coltheart's N (Coltheart, Davelaar, Jonasson and Besner 1977), another well documented effect related to word processing, refers to the number and relative frequency of neighbours, i.e., words differing by a single letter (such as banish and vanish). Evidence from this type of research has not always given consistent results, and reviewing them is beyond the scope of this paper. However, we stand by the remark of Bowers, Davis and Hanley (2005b) relative to the fact that in competitive network models like Interactive Activation Models (McClelland and Rumelhart 1981) and SOLAR models (Self-Organizing Lexical Acquisition and Recognition, Davis 1999) the critical contrast is between words that have no neighbours ('hermits') and words that have one or more neighbours. As noticed by the same authors (Bowers et al. $2005 \mathrm{~b})$, it is important to have a psychologically accurate definition of what is a neighbour and considering as such only words of the same length that differ by one letter (Coltheart's N) is based on simplicity rather than perceptual similarity.

Given that morphological processing depends on family members acting as synagonists (MFS), it may also be sensitive to the number/nature of similar in form lexical units which could act as antagonists, leading to interference in target identification and delaying morphological processing. Voga and Giraudo (2009) presented two experiments exploring a novel variable, coined 'pseudo-family size', which is the opposite of the MFS. We examined inflectional priming for two kinds of stimuli: verbs coming from big pseudo-families and verbs coming from small or nonexistent pseudo-families, i.e. what Bowers et al. 2005b call 'hermits'. When a word such as portons ('we carry', where port-is the stem and -ons is the conjugation mark) is presented to the lexical processing system as a prime, it can potentially activate (at least) all words that share its initial letters, i.e. the letters of the stem. The verbal form portons has numerous 'pseudo-relatives' at the lexical level : portail 'portal', porte 'door', port 'harbour', portier 'porter', portion 'portion', portique 'porch', portrait 'portrait', portière 'door', portugais 'Portuguese', but also a 'true' neighbour (in the sense of banish-vanish): postons 'we mail'. Our working hypothesis was that all these pseudo-relatives will behave like competitors at the lexical level. On the other hand, a verb like mourir (infinitive form of the verb to die) is almost a hermit, since its only pseudo-relative is the rare mouron 'scarlet pimpernel', and will therefore receive a very small amount of competition on the lexical - word-form level. A word can belong to the pseudo-family of another word even if they don't share their stem: for example, 
Table 1. Stimuli sample and degree of prime-target orthographic overlap (letters, percentage) for the repetition, the two morphologically related (frequent and non-frequent inflection) and the unrelated conditions for the two types of target (large pseudo-family size PsFam + verbs, low- pseudo-family size PsFam- verbs) tested in Experiment 1a.

\begin{tabular}{|c|c|c|c|c|c|c|c|}
\hline Exp. 1a & \multicolumn{7}{|c|}{ Primes } \\
\hline Word & Targets & Rep. & $\begin{array}{l}\text { Freq. } \\
\text { Infl. }\end{array}$ & $\begin{array}{l}\text { Orth. } \\
\text { overlap }\end{array}$ & Non-freq. infl. & $\begin{array}{l}\text { Orth. } \\
\text { overlap }\end{array}$ & Unrel. \\
\hline $\begin{array}{l}\text { PsFam + } \\
\text { verbs }\end{array}$ & $\begin{array}{l}\text { monter } \\
\text { (climb) }\end{array}$ & monter & $\begin{array}{c}\text { monté } \\
\text { (climbed) }\end{array}$ & $\begin{array}{l}3.75 \mathrm{lt} . \\
(64 \%)\end{array}$ & $\begin{array}{l}\text { montais (I was } \\
\text { climbing) }\end{array}$ & $\begin{array}{l}3.75 \mathrm{lt} . \\
(66 \%)\end{array}$ & $\begin{array}{l}\text { perdre } \\
\text { (to lose) }\end{array}$ \\
\hline $\begin{array}{l}\text { PsFam- } \\
\text { verbs }\end{array}$ & $\begin{array}{l}\text { sentir } \\
\text { (feel) }\end{array}$ & sentir & $\begin{array}{l}\text { senti } \\
\text { (felt) }\end{array}$ & $\begin{array}{l}.07 \mathrm{lt} . \\
(69 \%)\end{array}$ & $\begin{array}{c}\text { sentiront } \\
\text { (they'll feel) }\end{array}$ & $\begin{array}{l}4.21 \mathrm{lt} . \\
(69 \%)\end{array}$ & $\begin{array}{l}\text { appeler } \\
\text { (to call) }\end{array}$ \\
\hline
\end{tabular}

portugais 'Portuguese', under our definition, is a pseudo-relative of portons because the stem of portons is a part of the superset portugais. The decision to include this type of pseudo-relative in the computation of pseudo-family size was based on previous studies emphasizing the role of the beginnings of words in lexical access (Humphreys, Evett and Quinlan 1990; Grainger, O'Regan, Jacobs and Segui 1992), as well as on studies on lexical co-activation (Bowers et al. 2005b). Consequently, this measure of pseudo-family should not be assimilated to stem homographs, such as those of Laudanna, Badecker and Caramazza (1989), ex. colpo - colpa ('blow' -'guilt'). In short, we can say that our definition of the pseudo-family size of a lexical entry is the sum of neighbours in the classic sense (Coltheart's N) and of all words sharing their stem with that entry, even if what remains once the stem is removed is not really an affix (e.g. portugais). The two levels of the pseudo-family size factor (PsFam), estimated with the help of the French dictionary Petit Robert by exhaustive inspection, defined two categories of target words, from large (PSFam +$)$ and from small pseudo-families (PsFam-).

The experiments presented in Voga and Giraudo (2009) aimed also to investigate the influence of prime-target relative frequencies in masked priming. As mentioned above (section 2), what the majority of masked priming studies report to be morphological effects, is the facilitation induced by a morphologically related prime on its base-form target. This base-form target is the member of the morphological family that already has the greatest residual activation because of its frequency, generally higher than that of other morphologically related forms. As can be seen in Table 1, Experiment 1a studied this classic configuration, where the target is the easiest-to-activate member of the paradigm. Each target was given four types of prime: an identity prime, two morphologically related primes, i.e., a frequent inflection and a non-frequent one, and finally, an unrelated prime, relative to which priming effects were estimated. These primes define each one of the four experimental conditions for every type of verb, PSFam + and PsFam-.

The difference between the two experiments (see Table 2) is that while in Experiment 1a targets were always the infinitive form of French verbs, Experiment $1 \mathrm{~b}$ took as targets less frequent inflections, thus reversing the typical design: targets were 
Table 2. Examples of stimuli and frequencies (in occurrences per million) for materials used in experiments $1 \mathrm{a}$ and $1 \mathrm{~b}$ : targets and morphologically related primes, frequent inflections $(\mathrm{F}+)$ and non-frequent inflections (F-) for the two types of verbs, PsFam + and PsFam-.

\begin{tabular}{|l|c|c|c|c|c|c|}
\hline & $\begin{array}{c}\text { Targets } \\
\text { Exp. 1a }\end{array}$ & $\begin{array}{c}\text { Inflections } \\
\mathrm{F}+\end{array}$ & $\begin{array}{c}\text { Inflections } \\
\mathrm{F}-\end{array}$ & $\begin{array}{c}\text { Targets } \\
\text { Exp. 1b }\end{array}$ & $\begin{array}{c}\text { Inflections } \\
\mathrm{F}+\end{array}$ & $\begin{array}{c}\text { Inflections } \\
\mathrm{F}-\end{array}$ \\
\hline PsFam + & monter & monté & montais & montons & monté & montais \\
verbs & 115.4 & 144.08 & 4.16 & 6.27 & 144.08 & 4.16 \\
\hline PsFam- & sentir 78.4 & senti 95 & sentiront & sentons & senti 95 & sentiront \\
verbs & & & 2.39 & 4.64 & & 2.39 \\
\hline
\end{tabular}

no longer the infinitive forms of French verbs (and French-like pseudoverbs), but their $1^{\text {st }} / \mathrm{PL}$ inflection. The aim of this manipulation was to modify the relative frequency between prime and target. For a language like French, where infinitive forms tend to have a higher surface frequency than conjugated forms, this means that (conjugated) targets will have a surface form frequency that is lower or equivalent to that of their inflections (see Table 2 for comparative frequencies of the materials used in Experiments 1a and 1b).

\section{I Results and discussion}

The main outcome of this study (see Table 3 for results) concerned the role of the pseudo-family size combined with frequency: ${ }^{3}$ under the conditions of Exp. 1a, only primes that were frequent inflections of the infinitive targets significantly facilitated processing ( +16 and $+36 \mathrm{~ms}$ ), relative to the unrelated baseline condition, whereas non-frequent inflections failed to induce any facilitation $(+1$ and $+9 \mathrm{~ms})$. The fact that lexical frequencies of the primes influenced processing of the targets provides another experimental demonstration that lexical frequency plays a role in morphological processing (e.g. for French, Giraudo and Grainger 2000; Meunier and Segui 1999 with spoken primes). In the classic configuration tested in Exp. 1a, we thus obtained the classic morphological priming effect induced by frequent inflections, which did not differ from identity priming: this first result cannot be integrated in any kind of mandatory decomposition approach, given that both inflections, frequent and non-frequent ones, are equally decomposable, there is therefore no reason for the frequent ones to prime and the non-frequent ones not to do so.

This pattern of results changes radically in Exp. 1b, where the placement of primes and targets is the opposite of what the literature usually examines and where the relative frequencies between primes and targets are modified. We observe that only PsFam- verbs, with no antagonists at the word-form level, manage to induce repetition and morphological facilitation relative to the unrelated baseline condition $(50,26$ and $22 \mathrm{~ms}$, respectively). For these verbs, the facilitation induced by $\mathrm{F}+$ and $\mathrm{F}$ - inflections was equivalent, both arithmetically and statistically. The interaction between the two controlled factors (prime type and pseudo-family size) is significant, contrary to Exp. 1a. 
Table 3: Reaction times (RT in milliseconds) for lexical decisions to targets in the repetition $(\mathrm{R})$, frequent inflection $(\mathrm{F}+)$, non-frequent inflection $(\mathrm{F}-)$ and unrelated $(\mathrm{U})$ prime conditions for the two categories of verbs, PsFam + and (PsFam-, tested in Voga and Giraudo's experiments (2009). The effects denoted by an asterisk are significant (for the statistical analysis, see Voga and Giraudo 2009).

\begin{tabular}{|l|c|c|c|c|c|l|l|}
\hline Words & $\begin{array}{c}\text { Repetition } \\
(\mathrm{R})\end{array}$ & $\begin{array}{c}\text { Frequent } \\
\text { inflections } \\
(\mathrm{F}+)\end{array}$ & $\begin{array}{c}\text { Nonfrequent } \\
\text { inflections } \\
(\mathrm{F}-)\end{array}$ & $\begin{array}{c}\text { Unrelated } \\
(\mathrm{U})\end{array}$ & \multicolumn{3}{|c|}{$\begin{array}{c}\text { Net Priming } \\
\text { Effects }\end{array}$} \\
\hline Exp. 1a & RT & RT & RT & RT & U - R & U - F+ & U - F- \\
\hline $\begin{array}{c}\text { PsFam + } \\
\text { verbs }\end{array}$ & 602 & 617 & 633 & 634 & $32^{*}$ & $16^{*}$ & 1 \\
\hline $\begin{array}{c}\text { PsFam- } \\
\text { verbs }\end{array}$ & 593 & 597 & 624 & 633 & $40^{*}$ & $36^{*}$ & 9 \\
\hline Exp. 1b & RT & RT & RT & RT & U - R & U - F+ & U - F- \\
\hline $\begin{array}{c}\text { PsFam + } \\
\text { verbs }\end{array}$ & 638 & 663 & 629 & 652 & 14 & -11 & 23 \\
\hline $\begin{array}{c}\text { PsFam- } \\
\text { verbs }\end{array}$ & 594 & 618 & 622 & 644 & $50^{*}$ & $26^{*}$ & $22^{*}$ \\
\hline
\end{tabular}

In Exp. 1a, exactly as in the majority of similar experiments examining repetition and morphological effects in which the target is the easiest-to-activate member of the paradigm, repetition priming was statistically equivalent to morphological priming from frequent inflections. The fact that, in Exp. 1b, repetition conditions considerably differ from morphological priming, is a hint that we are not looking at inflection effects through the same window as in the majority of studies. The second result pointing us in this direction, is the failure of PsFam + frequent inflections to prime in Exp. 1b, despite the fact that these same verbs have exhibited significant inflectional priming in Exp. 1a (although not of the same amplitude than PsFam-verbs). At the same time, we observe that as soon as relative frequencies between primes and targets have been modified, thus leaving more time for activation/inhibition from other units to emerge, PsFam- verbs induce robust identity priming and significant inflectional priming, equivalent for frequent and non-frequent inflections.

In conclusion, the experiment we briefly presented here provides evidence for two facts that should be taken in consideration when designing, interpreting and modelling morphological priming data. The first one is that morphological priming effects depend not only on lexical frequency of the word-forms taken individually as materials for the experiment, but also on their relative frequencies. Arguing that the lexical variable called frequency leaves morphological processing unaffected because the locus of morphological priming effects is situated below the level of lexical identification, i.e., either at the morpho-orthographic level proceeding sublexically, or at the morpho-semantic level, operating at a more central locus within the mental lexicon, but still containing morphemes (in the Crepaldi et al. 2010 model), is totally incompatible with our data. This model is also incompatible with other data demonstrating that frequencies influence morphological processing (e.g. Giraudo and 
Grainger 2000, Burani and Thornton 2003; Voga, Giraudo and AnastassiadisSymeonidis 2012).

The second fact is that the pseudo-family size variable, an exo-lexical variable springing not from the word itself, but from the 'lexical environment' of the word-to-be-identified, influences inflectional processing. This influence, generated by the inhibition exerted from other words similar in form but morphologically unrelated, i.e. the pseudo-relatives of targets, points to the following idea: morphological processing effects are the sum of various kinds of activation and inhibition, situated at different levels, and not simply the result of a unique, universal and mandatory segmenting-into-morphemes (and pseudo-morphemes) mechanism.

\section{Conclusions - General discussion}

The above review and the experimental data we briefly described aimed to emphasize the great complexity of the flow of activation which the masked priming technique deals with. First of all, morphological processing effects are not independent of form and visual factors: we shouldn't forget that this technique, initially developed to study form factors in lexical access (for a review, see Forster, Mohan and Hector 2003), is sensitive to perceptual similarity between primes and targets, and that priming effects can be task-specific, e.g., present in a lexical decision task but absent in a same-different task (Kinoshita and Lupker 2003; Norris and Kinoshita 2008; see also Baayen 2014). Second, morphological processing effects are related to the units or sub-units frequency (section 2), as well as to the relative frequency between primes and targets. The results reported here (exp. 1a and 1b) demonstrated the interaction between frequency and pseudo-family size during processing French inflections: this leads us to conclude that the choice of a majority of processing studies consisting of presenting as target the easiest-to-activate member of the paradigm (or family), does not tell the whole story. The 'ritual' of presenting stimuli in a certain way, i.e. where the word-to-be-identified is the item which is going to pop-up immediately because of its low activation threshold, compared to other members of the paradigm/family, induces results reflecting a linear, single-channelled bottom-up view of the lexicon. We demonstrated that masked priming can and should be used to explore effects related, more or less directly, to the paradigmatic relations inherent to morphology. This set of relations has been clearly neglected until now by the psycholinguistic literature on processing, mostly preoccupied by the purely syntagmatic and formal aspects, failing to address some basic questions related to morphologically complex stimuli, such as the 'close-to-lexical' character of 'morphologically derived' nonwords (section 3). From this point of view, the insistence on arguing that the very existence of nonword morphological-like effects (e.g. sportation - sport), automatically invalidates any influence related to lexical identification, is symptomatic of this tendency.

The masked priming technique has a great potential for exploring the paradigmatic organization of language(s) (Corbin 1987/1991; Bybee 1988; 2007; Booij 2002; 2015), which brings us to the third type of factor examined here: the pseudo-family size is not a paradigmatic variable in the strict sense, it's nevertheless based on the same logic as 
the MFS, except the other way round in activation terms, i.e., it reflects the number of words that will function as antagonists and not as synagonists. From this point of view, the pseudo-family size is a variable that could be associated to discrimination-based indicators of language processing (Milin, Feldman, Ramscar, Hendrix and Baayen 2017). This variable highlights the fact that morphological priming effects do not exclusively depend on what happens inside the word, but also beyond the-word-to-be identified, in its lexical environment. By 'lexical environment' we refer to a dynamic network, compatible with facts such as productivity, lexical creation, lexical interference and competition (Hoffmann and Jacobs 2014) as well as facts related to discrimination processes (Milin et al. 2017). This lexical environment does not only exert positive influence (activation) but can also induce interference or competition, leading to inhibition. Visualizing this complex set of activation/inhibition in terms of a unique, purely bottom-up linear process, whose function would consist of segmenting the word-to-be-identified into pieces, seems largely insufficient. The inadequacy of the 'blind decomposition' lexical access logic to account for morphological effects has been underlined by several pieces of behavioural evidence for various languages (e.g. Giraudo and Grainger 2001; Pastizzo and Feldman 2002; Voga, Giraudo and Anastassiadis-Symeonidis 2012; Giraudo and Voga 2016, among many others), as well as in theoretical accounts such as Naïve Discriminative Learning (e.g. Baayen and Ramscar 2015, Milin et al. 2017).

Our conclusion is that the above considerations, along with a great deal of experimental data stemming from various techniques, and especially masked priming, strengthen the idea that the readers' morphological representation plays a central role in the organization of their mental lexicon. The role of perceptive salience (Giraudo and Dal Maso 2016b), i.e. of surface morphemes ${ }^{4}$ is certainly very important, especially in bottom-up protocols, however it constitutes merely 'the tip of the iceberg'. Unravelling the complex organizational principles at the interface of form and semantics, which constitute its hidden part, requires us to include variables related to the lexical status of items such as frequency, as well as paradigmatic relations and factors outside the word-to-be-studied.

\section{Notes}

1. The first word (or item) is the prime and the second is the target, as in corner-corn or, further, $\% \% \% \% d a d-I G U A L D A D$. It is also interesting to note that in a significant proportion of psycholinguistic studies, as in the studies cited here, the category of semantically opaque items mixes morphologically complex words, whose structure is opaque as a result of complex etymology but remains relatively accessible synchronically (e.g. fauvette), with morphologically simple words whose surface can be segmented into morpheme-like sub-units, e.g. corn-er, in Rastle et al. (2000), chant-ier, in Longtin and Meunier (2005), without making any difference between them.

2. In French, Giraudo and Grainger (2001) systematically compared morphologically complex words like laitage 'dairy' to orthographic controls like laitue 'lettuce' (see Experiment 2). 
3. An ANOVA was performed on these data with prime type (identity, frequent inflection, less frequent inflection, unrelated) and verb category (large pseudo-family size, small pseudo-family size) as within-participant factor.

4. We can imagine that other salient parts of words, different from surface morphemes are coded in the lexicon, ex. phonaesthemes (Bergen, 2004).

\section{References}

Amenta, Simona \& Davide Crepaldi 2012. Morphological processing as we know it: An analytical review of morphological effects in visual word identification. Frontiers in Language Sciences 3: 232.

Aronoff, Mark 1994. Morphology by itself. Cambridge: MIT Press.

Aronoff, Mark 2007. In the beginning was the word. Language 83(4): 803-30.

Aronoff, Mark \& Kirsten Fudeman 2005. What is morphology? Malden MA: Blackwell.

Baayen, Harald 2014. Experimental and psycholinguistic approaches to studying derivation. In Rochelle Lieber \& Pavol Štekauer (eds.), The Oxford handbook of derivational morphology. Oxford: Oxford University Press. 95-117.

Baayen, R. Harald \& Michael Ramscar 2015. Abstraction, storage and naive discriminative learning. In Ewa Dabrowska \& Dagmar Divjak (eds.), Handbook of cognitive linguistics. Berlin: De Gruyter Mouton. 99-120.

Bergen, Benjamin K. 2004. The psychological reality of phonaesthemes. Language 80(2): 290-311.

Bertram, Raymond, R. Harald Baayen \& Robert Schreuder 2000. Effects of family size for complex words. Fournal of Memory and Language 42: 390-405.

Beyersmann, Elisabeth, Jon Andoni Duñabeitia, Manuel Carreiras, Max Coltheart \& Anne Castles 2013. Early morphological decomposition of suffixed words: Masked priming evidence with transposed-letter nonword primes. Applied Psycholinguistics 34(5): 869-892.

Blevins, James P. 2006. Word-based morphology. Journal of Linguistics 42: 531-573.

Booij, Geert 2002. The morphology of Dutch. Oxford: Oxford University Press.

Booij, Geert 2015. Construction Morphology. In Andrew Hippisley \& Gregory Stump (eds.), The Cambridge handbook of morphology. Cambridge: Cambridge University Press. 424-448.

Bowers, Jeffrey S., Colin J. Davis \& Derek Hanley 2005a. Interfering neighbours: The impact of novel word learning on the identification of visually similar words. Cognition 97(3): B45-B54.

Bowers, Jeffrey S., Colin J. Davis \& Derek Hanley 2005b. Automatic semantic activation of embedded words: Is there a 'hat' in 'that'?, Fournal of Memory and Language 52: $131-143$

Burani, Cristina, Francesca M. Dovetto, Anna M. Thornton \& Alessandro Laudanna 1997. Accessing and naming affixed pseudo-words. In Geert Booij \& Jaap van Marle (eds.), Yearbook of Morphology 1996. Dordrecht: Kluwer. 55-72.

Burani, Cristina, Dario Salmaso \& Alfonso Caramazza 1984. Morphological structure and lexical access. Visible Language 18: 342-352.

Burani, Cristina, Stefania Marcolini \& Giacomo Stella 2002. How early does morpholexical reading develop in readers of a shallow orthography? Brain $E$ Language 81(1-3): 568-586.

Burani, Cristina \& Anna M. Thornton 2003. The interplay of root, suffix and whole-word frequency in processing derived words. In R. Harald Baayen, Robert Schreuder (eds.), Morphological Structure in Language Processing. Berlin: Mouton de Gruyter. 157-208. 
Bybee, Joan 1988. Morphology as lexical organisation. In M. Hammond and M. Noonan (eds.), Theoretical morphology: Approaches to modern linguistics. San Diego: Academic Press. $119-142$.

Bybee, Joan 2007. Frequency of use and the organisation of language. Oxford: Oxford University Press.

Caramazza, Alfonso, Alessandro Laudanna \& Cristina Romani 1988. Lexical access and inflectional morphology. Cognition 28: 297-332.

Christianson, Kiel, Rebecca L. Johnson \& Keith Rayner 2005. Letter transpositions within and across morphemes. Fournal of Experimental Psychology: Learning, Memory and Cognition 31: 1327-1339.

Coltheart, Max, Eileen Davelaar, Jon Torfi Jonasson \& Derek Besner 1977. Access to the internal lexicon. In Stan Dornic (ed.), Attention and Performance VI. New York: Academic Press. 535-555.

Corbin, Danielle 1987/1991. Morphologie derivationnelle et structuration du lexique, vol. 2. Tubingen/Villeneuve d'Ascq: Max Niemeyer Verlag / Presses Universitaires de Lille.

Crepaldi, Davide, Kathleen Rastle, Max Coltheart \& Lyndsey Nickels 2010. Fell primes fall but does bell prime ball? Masked priming with irregularly inflected primes. Fournal of Memory and Language 63: 83-99.

Crepaldi, Davide, Lara Hemsworth, Matthew J. Davis \& Kathleen Rastle 2016. Masked suffix priming and morpheme positional constraints. Quarterly Fournal of Experimental Psychology, 69(1): 113-28.

Davis, Colin John 1999. The self-organizing lexical acquisition and recognition SOLAR model of visual word recognition. Unpublished doctoral dissertation, University of New South Wales.

Davis, Matthew H. \& Kathleen Rastle 2010. Form and meaning in early morphological processing: Comment on Feldman, O’Connor, and Moscoso del Prado Martín. Psychonomic Bulletin E Reviem 17(5): 749-755.

Davis, Colin J. \& Stephen J. Lupker 2006. Masked inhibitory priming in English: Evidence for lexical inhibition. Fournal of Experimental Psychology: Human Perception and Performance 32(3): $668-687$.

De Jong, Nivja H., Laurie B. Feldman, Robert Schreuder, Matthew Pastizzo \& Harald Bayen 2002. The processing and representation of Dutch and English compounds: Peripheral morphological, and central orthographic effects. Brain and Language 81: 555-567.

De Jong, Nivja H., Robert Schreuder \& Harald Baayen 2000. The morphological size effect and morphology. Language and Cognitive Processes 15: 329-365.

Diependaele, Kevin, Joanna Morris, Raphael M. Serota, Daisy Bertrand \& Jonathan Grainger 2013. Breaking boundaries: Letter transpositions and morphological processing. Language and Cognitive Processes 28(7): 988-1003.

Diependaele, Kevin, Dominiek Sandra \& Jonathan Grainger 2005. Masked cross-modal morphological priming: Unravelling morpho-orthographic and morpho-semantic influences in early word recognition. Language and Cognitive Processes 20: 75-114.

Diependaele, Kevin, Dominiek Sandra \& Jonathan Grainger 2012. Derivational morphology and skilled reading: an empirical overview. In Michael Spivey, Ken MacRae \& Mark Joanisse (eds.), The Cambridge handbook of psycholinguistics. Cambridge UK: Cambridge University Press. 311-332. 
Duñabeitia, Jon Andoni, Manuel Perea \& Manuel Carreiras 2007. Do transposed-letter similarity effects occur at a morpheme level? Evidence for morpho-orthographic decomposition. Cognition 105(3): 691-703.

Duñabeitia, Jon Andoni, Manuel Perea \& Manuel Carreiras 2008. Does darkness lead to happiness? Masked suffix priming effects. Language and Cognitive Processes 23: $1002-1020$.

Duñabeitia, Jon Andoni, Manuel Perea \& Manuel Carreiras 2014. Revisiting letter transpositions within and across morphemic boundaries. Psychonomic Bulletin ES Reviem 21(6): 1557-1575.

Feldman, Laurie B., Patrick A. O'Connor \& Firmin M. Del Prado Martín 2009. Early morphological processing is morphosemantic and not simply morpho-orthographic: A violation of form-then-meaning accounts of word recognition. Psychonomic Bulletin $\mathbb{E}$ Reviem 16(4): 684-691.

Fliatouras, Asimakis, Madeleine Voga \& Anna Anastassiadis-Syméonidis forthcoming. L'étymologie populaire comme mécanisme de changement linguistique: apport des données du grec. Cahiers Balkaniques.

Ford, M. A., Matthew H. Davis \& William D. Marslen-Wilson 2010. Derivational morphology and base morpheme frequency. Fournal of Memory and Language 63: 117-130.

Forster, Kenneth I. 1976. Accessing the internal lexicon. In R. J. Wales \& Edward C. T. Walker, Nem approaches to language mechanisms. Amsterdam: North Holland. 256-287.

Forster, Kenneth I. \& Jonathan C. Forster 2003. DMDX: A Windows display program with millisecond accuracy. Behavioral Research Methods: Instruments $E$ Computers 35: 116-124.

Forster, Kenneth I., Kathleen Mohan \& Jo Hector 2003. The mechanics of masked priming. In Sachiko Kinoshita \& Stephen J. Lupker (eds.). Masked priming: State of the art. New York \& Hove, UK: Psychology Press. 3-37.

Giraudo, Hélène \& Serena Dal Maso 2016a. Suffix perceptual salience in morphological masked priming. Lingue e Linguaggio 15(1): 83-104.

Giraudo, Hélène \& Serena Dal Maso 2016b. The salience of complex words and their parts: Which comes first? Frontiers in Psychology 7: 1778.

Giraudo, Hélène \& Jonathan Grainger 2000. Effects of prime word frequency and cumulative root frequency in masked morphological priming. Language and Cognitive Processes 15: $421-444$.

Giraudo, Hélène \& Jonathan Grainger 2001. Priming complex words: Evidence for supralexical representation of morphology. Psychonomic Bulletin and Reviem 81: 127-131.

Giraudo, Hélène \& Jonathan Grainger 2003. A supralexical lexical model for French derivational morphology. In Egbert M. H. Assink \& Dominiek Sandra (eds). Reading Complex Words: Cross-language Studies. New York: Kluwer Academic. 139-157.

Giraudo, Hélène \& Madeleine Voga 2013. Prefix units within the mental lexicon. In Nabil Hathout, Fabio Montermini \& Jesse Tseng (eds.), Morphology in Toulouse. Selected Proceedings of Décembrettes 8. Munich: Lincom Europa. 61-78.

Giraudo, Hélène \& Madeleine Voga 2016. Words matter more than morphemes: An investigation of masked priming effects with complex words and nonwords. Italian Fournal of Linguistics 28(1): 49-78.

Grainger, Jonathan, Pascale Colé \& Juan Segui 1991. Masked morphological priming in visual word recognition. Fournal of Memory and Language 30: 370-384. 
Grainger, Jonathan \& A. M. Jacobs 1996. Orthographic processing in visual word recognition: A multiple read-out model. Psychological Reviem 103: 518-565.

Grainger, Jonathan, J. Kevin O'Regan, Arthur M. Jacobs \& Juan Segui 1992. On the role of competing word units in visual word recognition: The neighbourhood frequency effect. Perception and Psychophysics 45: 189-195.

Hathout, Nabil 2009. Acquisition of morphological families and derivational series from a machine readable dictionary. In Fabio Montermini, Gilles Boyé \& Jesse Tseng (eds.), Selected Proceedings of the 6th Décembrettes: Morphology in Bordeaux. Cambridge, Mass.: Cascadilla Proceedings Project. 166-180.

Hay, Jennifer \& Harald Baayen 2003. Phonotactics, parsing and productivity. Italian Fournal of Linguistics 1: 99-130.

Hofmann, Markus J. \& Arthur M. Jacobs 2014. Interactive activation and competition models and semantic context: from behavioral to brain data. Neuroscience and Biobehavioral Reviems 46: 85-104.

Humphreys, Glyn W., Lindsay J. Evett \& Philip T. Quinlan 1990. Orthographic processing in visual word identification. Cognitive Psychology 22: 517-560.

Jacobs, Arthur M., Ralf Graf \& Annette Kinder 2003. Receiver-operating characteristics in the Lexical Decision Task: Evidence for a simple signal detection process simulated by the multiple read-out model. Fournal of Experimental Psychology: Learning, Memory E Cognition 29(3): 481-488.

Jacobs, A. M. \& Jonathan Grainger 1994. Models of visual word recognition - Sampling the state of the art. Fournal of Experimental Psychology: Human Perception and Performance 20: $1311-1334$.

Kinoshita, Sachiko \& Stephen Lupker 2003. Masked priming: The state of the art. New York \& Hove, UK: Psychology Press.

Laudanna, Alessandro, William Badecker \& Alfonso Caramazza 1989. Priming homographic stems. Fournal of Memory and Language 28: 531-546.

Longtin, Catherine-Marie, Juan Segui \& Pierre A. Hallé 2003. Morphological priming without morphological relationship. Language and Cognitive Processes 18(3):313-334.

Longtin, Catherine-Marie \& Fanny Meunier 2005. Morphological decomposition in early visual word processing. Fournal of Memory and Language 53(1): 26-41.

López-Villaseñor, Miguel Lázaro 2012. The effects of base frequency and affix productivity in Spanish. The Spanish Fournal of Psychology 15(2): 505-512.

Marantz, Alec 2013. No escape from morphemes in morphological processing. Language $\mathbb{E}$ Cognitive Processes 28(7): 905-916.

Massol, Stéphanie, Jonathan Grainger, Stéphane Dufau \& Phillip Holcomb 2010. Masked priming from orthographic neighbors: An ERP investigation. Fournal of Experimental Psychology: Human, Perception and Performance 36(1): 162-174.

McClelland, James L. \& David E. Rumelhart 1981. An interactive activation model of context effects in letter perception: Part 1. An account of basic findings. Psychological Reviem 88: 375-407.

McCormick, Samantha, Marc Brysbaert \& Kathleen Rastle 2009. Is morphological decomposition limited to low-frequency words? Quarterly Fournal of Experimental Psychology 62: 1706-1715.

McCormick, Samantha F., Kathleen Rastle \& Matthew H. Davis 2008. Is there a 'fete' in 'fetish'? Effects of orthographic opacity on morpho-orthographic segmentation in visual word recognition. Fournal of Memory and Language 58: 307-326. 
Meunier, Fanny \& Catherine-Marie Longtin 2007. Morphological decomposition and semantic integration in word processing. Fournal of Memory and Language 56: 457-471.

Meunier, Fanny \& Juan Segui 1999. Morphological priming effect: the role of surface frequency. Brain and Language 68: 54-60.

Milin, Petar, Laurie B. Feldman, Michael Ramscar, Peter Hendrix \& Harald Baayen 2017. Discrimination in lexical decision. PLoS ONE 12(2):e0171935. https://doi.org/10.1371/ journal.pone.0171935.

Morris, Joanna, Jonathan Grainger \& Phillip J. Holcomb 2013. Tracking the consequences of morpho-orthographic decomposition using ERPs. Brain Research 1529: 92-104.

Moscoso del Prado Martín, Fermín, Avital Deutsch, Ram Frost, Robert Schreuder, Nivja H. De Jong \& R. Harald Baayen 2005. Changing places: a cross-language perspective of the role of morphology in the processing of Hebrew and Dutch. Fournal of Memory and Language 53: 496-512.

Mulder, Kimberley, Teun Dijkstra, Robert Schreuder \& R.Harald Baayen 2014. Effects of primary and secondary morphological family size in monolingual and bilingual word processing. Fournal of Memory and Language 72: 59-84.

Norris, Dennis \& Sachiko Kinoshita 2008. Perception as evidence accumulation and Bayesian inference: Insights from masked priming. Fournal of Experimental Psychology: General 137(3): 434-455.

Pastizzo, Matthew J. \& Laurie Beth Feldman 2002. Discrepancies between orthographic and unrelated baselines in masked priming undermine a decompositional account of morphological facilitation. Fournal of Experimental Psychology: Learning, Memory and Cognition 28: 244-249.

Plag, Ingo 1999. Morphological productivity: Structural constraints in English derivation. Berlin, New York: Mouton de Gruyter.

Plag, Ingo 2004. Syntactic category information and the semantics of derivational morphological rules, Folia Linguistica 38(3-4): 193-225.

Rastle, Kathleen, Matthew H. Davis, William Marslen-Wilson \& Lorraine Tyler 2000. Morphological and semantic effects in visual word recognition: a time course study. Language and Cognitive Processes 15: 507-537.

Rastle, Kathleen \& Matthew H. Davis 2008. Morphological decomposition based on the analysis of orthography. Language and Cognitive Processes 23: 942-971.

Rastle, Kathleen, Matthew H. Davis \& Boris New 2004. The broth in my brother's brothel: Morpho-orthographic segmentation in visual word recognition. Psychonomic Bulletin and Reviem 11: 1090-1098.

Rueckl, Jay G. \& Anurag Rimzhim 2011. On the interaction of letter transpositions and morphemic boundaries. Language and Cognitive Processes 26: 482-508.

Sánchez-Gutiérrez, Claudia \& Kathleen Rastle 2013. Letter transpositions within and across morphemic boundaries: Is there a cross-language difference? Psychonomic Bulletin E Reviem 20(5): 988-996.

Saussure, Ferdinand de 2002. Écrits de linguistique générale, text compiled and edited by Simon Bouquet \& Rudolf Engler. Paris: Gallimard.

Schreuder, Robert \& R. Harald Baayen 1997. How complex simplex words can be. Fournal of Memory and Language 37: 118-139.

Segui, Juan \& Jonathan Grainger 1990. Priming word recognition with orthographic neighbors: Effects of relative prime-target frequency. Fournal of Experimental Psychology: Human Perception and Performance 16(1): 65-76. 
Taft, Marcus 1994. Interactive activation as a framework for understanding morphological processing. Language E Cognitive Processes 9: 271-294.

Taft, Marcus 2004. Morphological decomposition and the reverse base frequency effect. Quarterly Journal of Experimental Psychology 57A: 745-765.

Taft, Marcus \& Kenneth I. Forster 1975. Lexical storage and retrieval of prefixed words. Journal of Verbal Learning and Verbal Behavior 14: 638-647.

Voga, Madeleine \& Hélène Giraudo 2009. Pseudo-family size influences processing of French inflections: evidence in favor of a supralexical account. In Fabio Montermini, Gilles Boyé \& Jesse Tseng (eds.), Selected Proceedings of the 6th Décembrettes: Morphology in Bordeaux. Somerville, MA: Cascadilla Proceedings Project. 148-155.

Voga, Madeleine \& Hélène Giraudo \& Anna Anastassiadis-Symeonidis 2012. Differential processing effects within 2nd group Modern Greek verbs. Lingue e Linguaggio 2: 215-234.

Voga, Madeleine \& Jonathan Grainger 2004. Masked morphological priming with varying levels of form overlap: Evidence from Greek verbs. Current Psychology Letters: Behaviour, Brain $\mathbb{E}$ Cognition 13(2), http://cpl.revues.org/422

\author{
Author's address: (Madeleine Voga) \\ Université Paul-Valéry Montpellier III \\ Route de Mende \\ 34199 Montpellier Cedex 5 \\ France \\ E-mail: madeleine.voga@univ-montp3.fr \\ (Hélène Giraudo) \\ C528 Maison de la Recherche \\ Université de Toulouse Fean Faurès \\ 5 allées Antonio Machado \\ 31058 Toulouse Cedex 9 \\ France \\ E-mail: helene.giraudo@univ-tlse2.fr
}




\section{Your short guide to the EUP Journals Blog http://euppublishingblog.com/}

A forum for discussions relating to Edinburgh University Press Journals

\section{The primary goal of the EUP Journals Blog}

To aid discovery of authors, articles, research, multimedia and reviews published in Journals, and as a consequence contribute to increasing traffic, usage and citations of journal content.

\section{Audience}

Blog posts are written for an educated, popular and academic audience within EUP Journals' publishing fields.

\section{Content criteria - your ideas for posts}

We prioritize posts that will feature highly in search rankings, that are shareable and that will drive readers to your article on the EUP site.

\section{Word count, style, and formatting}

- Flexible length, however typical posts range 70-600 words.

- Related images and media files are encouraged.

- No heavy restrictions to the style or format of the post, but it should best reflect the content and topic discussed.

\section{Linking policy}

- $\quad$ Links to external blogs and websites that are related to the author, subject matter and to EUP publishing fields are encouraged, e.g.to related blog posts

\section{Submit your post}

Submit to ruth.allison@eup.ed.ac.uk

If you'd like to be a regular contributor, then we can set you up as an author so you can create, edit, publish, and delete your own posts, as well as upload files and images.

\section{Republishing/repurposing}

Posts may be re-used and re-purposed on other websites and blogs, but a minimum 2 week waiting period is suggested, and an acknowledgement and link to the original post on the EUP blog is requested.

\section{Items to accompany post}

- A short biography (ideally 25 words or less, but up to 40 words)

- A photo/headshot image of the author(s) if possible.

- Any relevant, thematic images or accompanying media (podcasts, video, graphics and photographs), provided copyright and permission to republish has been obtained.

- Files should be high resolution and a maximum of $1 \mathrm{~GB}$

- Permitted file types: jpg, jpeg, png, gif, pdf, doc, ppt, odt, pptx, docx, pps, ppsx, xls, xlsx, key, mp3, m4a, wav, ogg, zip, ogv, mp4, m4v, mov, wmv, avi, mpg, 3gp, $3 g 2$. 